\title{
Perencanaan Mitigasi Bencana Banjir Non-Struktural Di Daerah Aliran Sungai Comal Hilir, Jawa Tengah
}

\author{
Yunus Aris Wibowo ${ }^{1,2, *}$, Lintang Ronggowulan³, Dian Adhetya Arif ${ }^{4}$, Rikki Afrizal ${ }^{5}$, \\ Yaskinul Anwar ${ }^{6}$, Ayu Fathonah ${ }^{1}$ \\ ${ }^{1}$ Program Studi Pendidikan Geografi, Fakultas Keguruan dan Ilmu Pendidikan, Universitas \\ Muhammadiyah Surakarta, Surakarta 57162, Jawa Tengah, Indonesia; ${ }^{2}$ Pusat Studi Mitigasi Bencana, \\ Program Studi Pendidikan Geografi Universitas Muhammadiyah Surakarta, Surakarta 57162, Jawa \\ Tengah, Indonesia \\ ${ }^{3}$ Program Studi Pendidikan Geografi, Fakultas Keguruan dan Ilmu Pendidikan, Universitas Sebelas \\ Maret, Surakarta, Surakarta 57126, Jawa Tengah, Indonesia \\ ${ }^{4} J u r u s a n$ Geografi, Fakultas Ilmu Sosial, Universitas Negeri Padang, Padang 25713, Sumatera Barat, \\ Indonesia \\ ${ }^{5}$ Program Studi Perencanaan Wilayah dan Kota, Fakultas Teknik, Universitas Islam Kuantan Singingi, \\ Kuantan Singingi, Riau, Indonesia \\ ${ }^{6}$ Program Studi Pendidikan Geografi, Fakultas Keguruan dan Ilmu Pendidikan, Universitas \\ Mulawarman, Samarinda, Kalimantan Timur, Indonesia \\ Email : *yunus.a.wibowo@ums.ac.id, lintang_ronggowulan@staff.uns.ac.id, \\ dianadhetyaarif@gmail.com, Rikki.afrizal@mail.ugm.ac.id, yaskinul.anwar@fkip.unmul.ac.id, \\ a610160097@student.ums.ac.id
}

Dikirim : 1 September 2019

Diterima: 1 September 2019

\begin{abstract}
Abstrak: Banjir luapan sungai telah menjadi permasalahan bagi masyarakat yang bermukim di wilayah hilir Daerah Aliran Sungai. DAS Comal hilir hampir setiap tahun mengalami banjir yang diakibatkan meluapnya Sungai Comal. Oleh karena itu diperlukan upaya perencanaan mitigasi yang tepat. Studi ini menekankan pada penyusunan perencanaan mitigasi bencana banjir luapan sungai non-struktural. Pendekatan yang digunakan dalam studi ini adalah pendekatan kualitatif dengan desain penelitian studi literatur dan survei lapangan. Studi literatur dilakukankan untuk mengetahui riwayat dan area terdampak banjir di DAS Comal hilir, sedangkan survei lapangan dilakukan untuk mengetahui kondisi sosiokultural masyarakat. Hasil studi ini adalah perencanaan mitigasi bencana banjir luapan sungai nonstruktural di DAS Comal hilir yang terdiri atas perencanaan tata ruang wilayah yang selaras dengan pengelolaan penggunaan lahan di DAS Comal, deteksi dan prediksi kondisi debit Sungai Comal melalui pencatatan serta pengamatan data hidrometeorologi, perencanaan pengelolaan kawasan sempadan sungai, literasi kebencanaan di sekolah dan masyarakat, peningkatan sistem komunikasi dan kearifan lokal dalam masyarakat, pembuatan jalur evakuasi, sistem peringatan dini serta simulasi bencana serta reboisasi dan reforestasi. Perencanaan mitigasi tersebut tidak hanya menjadi tanggung jawab pemerintah saja, melainkan membutuhkan kesadaran dan kerjasama dari masyarakat.
\end{abstract}

Kata kunci: Banjir luapan sungai, mitigasi non-struktural, bencana, kerentanan, DAS Comal

Abstract: River flooding has become a serious disruption for community which lives in downstream area of a watershed. Comal Watershed is annually experience river flooding caused by Comal River. Therefore, it is necessary to proper mitigation planning. This study organized the arrangement of river flooding non-structural mitigation planning. Qualitative approach was used in this study; not to mention the research design utilzed literature study and field survey. Literature study was used for finding out the river flood events record and affected area in downdstream area of Comal Watershed. Meanwhile, field survey was conducted to overview the socio-cultural condition of the community which live in it. The results indicated that river flooding non-structural mitigation planning area in downdstream area of Comal Watershed consisted of spatial planning in harmony with landuse management of Comal Watershed, detection and prediction of the Comal River discharge conditions through recording and observing hydrometeorological data, management planning of riparian zone, Disaster literacy toward schools and community, community communication system improvement, local wisdom enhancement, 
evacuation route arrangement, early warning system utilization, disaster simulation and reforestation. Mitigation planning is not only the responsibility of the government, but requires awareness and cooperation from the community.

Keyword: River flooding, non-structural mitigation, disaster, vulnerability, Comal Watershed

\section{Pendahuluan}

Banjir luapan sungai telah menjadi salah satu isu penting bagi sebagian besar waterfront cities di Asia. Banjir luapan sungai merupakan salah satu gangguan yang berdampak besar bagi aktivitas manusia di negara-negara berkembang seperti Indonesia, India, Cina, Thailand, dan Vietnam. Fenomena tersebut bisa disebabkan oleh curah hujan tinggi yang dipicu oleh perubahan iklim, penurunan kapasitas tampung sungai karena sedimentasi, kegagalan perencanaan sempadan sungai dan alih fungsi lahan sebagai bentuk kurang efektifnya perencanaan tata ruang wilayah (Rezende, de Franco, de Oliveira, Jacob, \& Miguez, 2019; Wyżga, Kundzewicz, Konieczny, Piniewski, Zawiejska, \& Radecki-Pawlik, 2018). Banyak kota khususnya kota-kota pesisir di beberapa provinsi di Indonesia menghadapi permasalahan serius karena banjir luapan sungai seperti Jakarta, Tegal, Cirebon, Pemalang, Pekalongan, Semarang, Surabaya. Sebagian besar kejadian-kejadian banjir melanda Provinsi Jawa Timur dengan 99 kejadian dan Provinsi Jawa Tengah dengan 91 kejadian (Badan Perencanaan Pembangunan Daerah Provinsi Jawa Tengah, 2005). Namun demikian, kejadian-kejadian banjir luapan sungai di Provinsi Jawa Tengah merupakan kejadian dengan dampak yang sangat besar bagi kehidupan masyarakat (Marfai, et al., 2008).

Sebagian besar kejadian banjir luapan sungai di Provinsi Jawa Tengah juga merupakan kejadian yang hampir pasti terjadi ketika musim hujan di wilayah Indonesia tiba. Hal itu dibuktikan dengan data dari Badan Perencanaan Pembangunan Daerah (BAPPEDA) Provinsi Jawa Tengah yang mencatat lebih dari 25 kota/kabupaten di Jawa Tengah sangat rawan terhadap banjir luapan sungai (Badan Perencanaan Pembangunan Daerah Provinsi Jawa Tengah, 2005). Sebagian besar wilayah Jawa Tengah menghadapi curah hujan dengan frekuensi dan intesitas yang tinggi pada Bulan Desember sampai Maret. Jika curah hujan tinggi memicu peningkatan debit yang dapat melampaui kapasitas tampung sungai maka banjir terjadi (Reisenbüchler, Bui, Skublics, \& Rutschmann, 2019), dan jika banjir tersebut menggenang serta mengganggu aktivitas masyarakat maka sudah bisa dikategorikan sebagai bencana.

Riset-riset telah dilakukan baik oleh pemerintah maupun kalangan akademisi di kota-kota di wilayah kepesisiran Jawa Tengah yang rawan terhadap bencana banjir luapan sungai seperti Semarang, Tegal, Pekalongan, Demak, Rembang. Namun, Kabupaten Pemalang yang juga terletak di wilayah kepesisiran utara Jawa Tengah masih belum dikaji secara mendalam, dibuktikan belum banyak riset dan tindakan perencanaan mitigasi yang tepat terhadap bencana banjir luapan sungai. Oleh karena itu, riset terkait bencana banjir luapan Sungai Comal Wilayah Kabupaten Pemalang menjadi sangat penting dan menarik.

Wilayah Kabupaten Pemalang yang rawan terhadap bencana banjir luapan Sungai Comal sebagian besar merupakan wilayah hilir DAS Comal. Wilayah tersebut telah berkembang menjadi pusat pertumbuhan baru karena relatif dekat dengan pusat pemerintahan dan dilalui oleh jalur utama yang menghubungkan Jawa bagian barat, tengah dan timur atau jamak disebut jalur pantai utara. Hal itu sekaligus mengindikasikan bahwa wilayah tersebut menjadi sangat rentan baik secara sosial, fisik, ekonomi, maupun lingkungan. Masyarakat yang tinggal di wilaya hilir DAS Comal menjadi sangat rentan karena harus menghadapi kejadian banjir luapan sungai setiap tahun.

DAS Comal secara dominan berada di wilayah administrasi Kabupaten Pemalang. DAS Comal merupakan salah satu DAS kritis yang masuk kategori super prioritas penanganan (Keputusan Menteri Kehutanan dan Perkebunan, 2009). Penanganan atau perencanaan 
pengelolaan DAS yang baik dapat mengurangi potensi banjir luapan sungai. Pengelolaan DAS yang tepat dapat pula menjadi bentuk mitigasi bencana banjir luapan sungai. Mitigasi bencana yang terencana dengan baik dapat menciptakan ketangguhan bencana. Perencanaan mitigasi merupakan upaya-upaya yang dilakukan untuk mengurangi risiko bencana melalui pengembangan/pembangunan aspek fisik dan/atau peningkatan kesadaran dan coping capacity masyarakat terhadap bencana (Rezende, de Franco, de Oliveira, Jacob, \& Miguez, 2019). Uraian tersebut dapat dijabarkan dan dilaksanakan secara struktural maupun non-struktural (Itsukushima, 2018). Mitigasi struktural meliputi pembangunan fisik secara keteknikan seperti pembangunan dam, tanggul buatan, saluran drainase maupun kolam tampungan, sedangkan mitigasi non-struktural meliputi aspek sosial, pendidikan, kemasyarakatan, penghijauan, dan reboisasi (Jamrussri \& Toda, 2017; Kai, Deyi, \& Zhaohui, 2016 ).

Kejadian bencana mungkin tidak bisa sepenuhnya dihilangkan, tetapi dampak dari kejadian tersebut dapat dikurangi (Kiedrzynska, Kiedrzynski, \& Zalewski, 2014). Seiring dengan peningkatan intensitas maupun frekuensi kejadian bencana banjir luapan sungai maka mitigasi secara struktural saja menjadi tidak cukup lagi untuk menanggulangi bencana banjir. Masyarakat sebagai korban yang paling terdampak ketika bencana banjir melanda merupakan objek penting yang harus ditingkatkan kapasitasnya (coping capacity) dalam menghadapi bencana tersebut. Peningkatan kapasitas masyarakat tersebut merupakan bagian dari upaya mitigasi non-struktural.

Jika kapasitas masyarakat yang tinggal pada wilayah rawan bencana banjir luapan sungai dapat ditingkatkan maka kerentanan masyarakat tersebut bencana akan menurun karena telah siap menghadapi kemungkinan terburuk. Dengan kapasitas yang baik dan tepat, masyarakat mampu melaksanakan persiapan yang lebih matang, dapat menyelamatkan keluarga, orangorang di sekitarnya dan juga harta benda yang dimiliki ketika banjir melanda. Oleh karena itu, perencanaan mitigasi non-struktural menjadi bagian sangat penting dalam upaya pengurangan risiko bencana karena bersentuhan langsung dengan masyarakat khususnya yang terdampak atau berpotensi terdampak bencana banjir luapan sungai. Studi ini fokus untuk menemukenali perencanaan mitigasi non-struktural yang tepat di wilayah hilir DAS Comal, Kabupaten Pemalang dengan memperhatikan riwayat kejadian banjir dan kerentanan (fisik, sosial, ekonomi, lingkungan). Diharapkan dengan adanya perencanaan mitigasi tersebut masyarakat di wilayah hilir DAS Comal dapat tumbuh menjadi masyarakat tangguh bencana.

\section{Metode Penelitian}

Studi ini dilakukan di DAS Comal hilir, Kabupaten Pemalang, Jawa Tengah (Gambar 1). Wilayah tersebut merupakan wilayah dengan topografi dataran dengan kemiringan lereng 0$2 \%$ berdasarkan klasifikasi van Zuidam. Wilayah tersebut terdiri atas enam wilayah administrasi kecamatan, yaitu Kecamatan Ampelgading, Bantarbolang, Bodeh, Comal, Petarukan dan Ulujami. Studi ini termasuk jenis penelitian kualitatif dengan desain studi literatur dan survei lapangan. Desain tersebut dipilih dengan tujuan menghasilkan mitigasi bencana banjir non-struktutal yang efektif untuk menghadapi kemungkinan bencana terparah. Data riwayat banjir dapat menggambarkan beberapa kejadian banjir dengan intensitas dan frekuensi yang berbeda yang kemudian disesuaikan dengan bentuk mitigasi bencana banjir nonstruktural hasil studi literatur dan survei lapangan. Satuan analisis dalam penelitian ini adalah kelurahan/desa. 


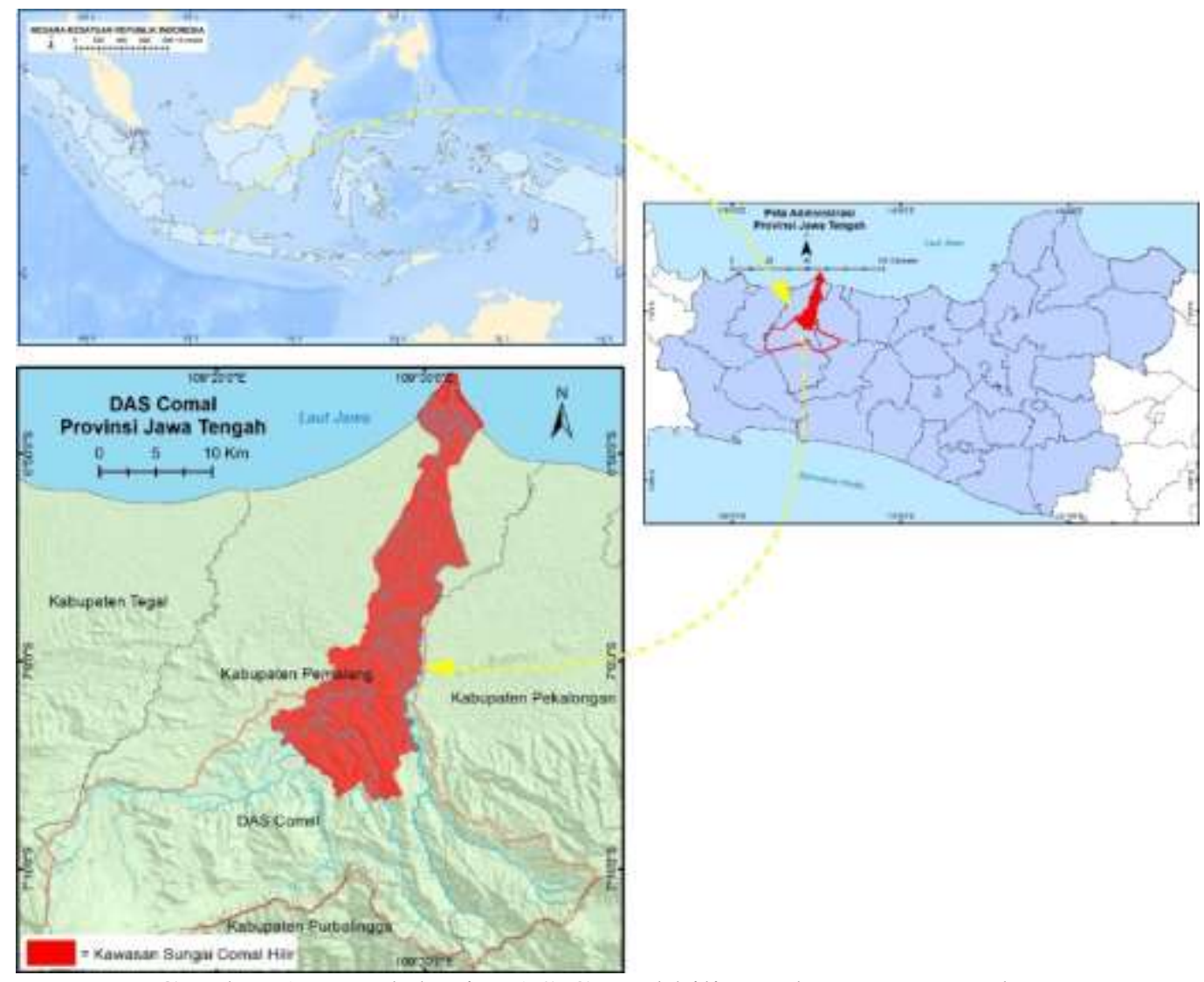

Gambar 1. Peta lokasi DAS Comal hilir, Kabupaten Pemalang

\section{Pengumpulan data}

Pengumpulan data diperoleh melalui studi literatur dari penelitian-penelitian terdahulu maupun data dari berbagai instansi dan hasil survei lapangan. Data-data tersebut digunakan sebagai dasar analisis bahaya banjir, kerentanan terhadap banjir dan untuk merumuskan perencanaan mitigasi non-struktural sesuai dengan bahaya banjir serta kondisi kerentanan terhadap banjir di DAS Comal hilir. Bahaya banjir diperoleh dari pengumpulan data kejadian banjir di DAS Comal hilir baik secara temporal maupun spasial. Analisis dilakukan untuk mengetahui frekuensi, intensitas dan luasan area terdampak banjir.

\section{Analisis data}

Analisis kejadian banjir di DAS Comal hilir dilakukan dengan pengumpulan data dari instansi-instansi terkait bencana banjir di DAS Comal. Kemudian data-data tersebut disajikan secara spasial dalam bentuk peta area terdampak banjir untuk digunakan sebagai dasar analisis kerentanan terhadap banjir dan dasar analisis perencanaan mitigasi bencana banjir nonstruktural. Kerentanan terhadap banjir dilakukan dengan analisis komponen risiko untuk analisis kerentanan sosial, ekonomi, fisik dan lingkungan (Badan Nasional Penanggulangan Bencana, 2012; Kumpulainen, 2006; United Nations International Strategy for Disaster Reduction (UNISDR), 2009; Westen, Kingma, \& Montoya, 2009; Asian Disaster Preparedness Center (ADPC), 2005). Data-data tersebut diperoleh dari data dari Badan Pusat Statistik (BPS), Kabupaten Pemalang dan interpretasi citra satelit resolusi tinggi (CSRT). Data dari BPS digunakan untuk analisis kerentanan sosial, fisik dan ekonomi, sedangkan data interpretasi CSRT digunakan untuk analisis kerentanan lingkungan. Setelah bahaya banjir dan kerentanan terhadap banjir diketahui, selanjutnya dilakukan analisis untuk menentukan bentuk-bentuk mitigasi non-struktural di DAS Comal hilir. Bentuk-bentuk mitigasi tersebut diperoleh dari 
hasil studi literatur tentang mitigasi bencana banjir luapan sungai yang sudah berhasil diterapkan di lokasi lain dengan karakteristik yang sama dengan DAS Comal hilir, kemudian dilakukan penyesuaian antara bentuk-bentuk mitigasi tersebut dan bahaya banjir, kerentanan terhadap banjir serta hasil overview melalui survei lapangan.

\section{Hasil dan Pembahasan \\ Pemetaan area terdampak banjir luapan sungai di DAS Comal hilir}

Data area terdampak banjir di suatu wilayah baik wilayah administrasi maupun wilayah DAS dapat berupa data temporal dalam bentuk tabular maupun data spasial dalam bentuk peta atau data dasar spasial dalam format lain. Di antara kedua data tersebut, ditinjau dari sisi pemanfaatan untuk mitigasi bencana maka data yang ditampilkan dalam bentuk peta akan cenderung memudahkan perencanaan mitigasi bencana. Hal itu dikarenakan distribusi banjir dapat disajikan secara spasial. Jika data yang tersedia dalam bentuk tabular maka langkah awal adalah menyajikan data tersebut dalam bentuk spasial, yaitu peta.

Pemetaan area terdampak diperlukan untuk mengetahui area tergenang dan memperkirakan luasnya. Luas area terdampak banjir dapat digunakan sebagai salah satu indikator seberapa besar dampak banjir di wiliayah hilir DAS Comal. Pemetaan tersebut dapat dilakukan dengan berbagai metode, seperti interpretasi citra satelit, interpretasi foto udara, pemodelan banjir dan pemetaan partisipasi. Metode-metode tersebut memiliki beberapa perbedaan baik dari sisi kelebihan dan kekurangan yang terdiri dari kualitas serta akurasi peta hasil. Peta area terdampak banjir dapat disusun berdasarkan data satu waktu kejadian bencana banjir maupun data multitemporal. Data kejadian banjir di DAS Comal hilir diperoleh dari Badan Penanggulangan Bencana Daerah (BPBD), Dinas Sosial, Tenaga Kerja dan Transmigrasi (DINSOSNAKERTRANS) Kabupaten Pemalang dan Balai Pengelolaan Daerah Aliran Sungai (BPDAS) Pemali-Jratun. Data yang diperoleh dari BPBD dan DINSOSNAKERTRANS Kabupaten Pemalang dalam bentuk tabular dengan unit analisis administrasi kelurahan/desa yang kemudian diolah dan ditampilkan secara spasial dalam bentuk peta (Gambar 2). Data yang diperoleh dari BPDAS Pemali-Jratun dalam bentuk peta dengan satuan DAS, yaitu DAS Comal (Gambar 3). Oleh karena itu data-data tersebut dikombinasikan untuk mendapatkan distribusi bahaya banjir secara spasial di DAS Comal hilir.

Gambar 2 menyajikan data kejadian banjir pada Tahun 2014 dan 2015 (BPBD dan DINSOSNAKERTRANS Kabupaten Pemalang), sedangkan Gambar 3 menampilkan data hasil pemodelan dari BPDAS Pemali-Jratun. Peta yang dihasilkan menunjukkan bahwa DAS Comal hilir termasuk dalam wilayah rawan banjir luapan sungai. Wilayah yang berada dalam kawasan rawan bencana banjir meliputi 59 kelurahan/desa yang termasuk dalam lima kecamatan, yaitu Kecamatan Ampelgading, Bantarbolang, Bodeh, Comal, Petarukan dan Ulujami. Wilayah tersebut hampir setiap tahun dilanda banjir luapan Sungai Comal dengan frekuensi dan intensitas yang berbeda. Berdasarkan data kejadian banjir dari DINSOSNAKERTRANS Kabupaten Pemalang, kejadian banjir yang paling parah tercatat pada Tahun 1980 dan 2014. 


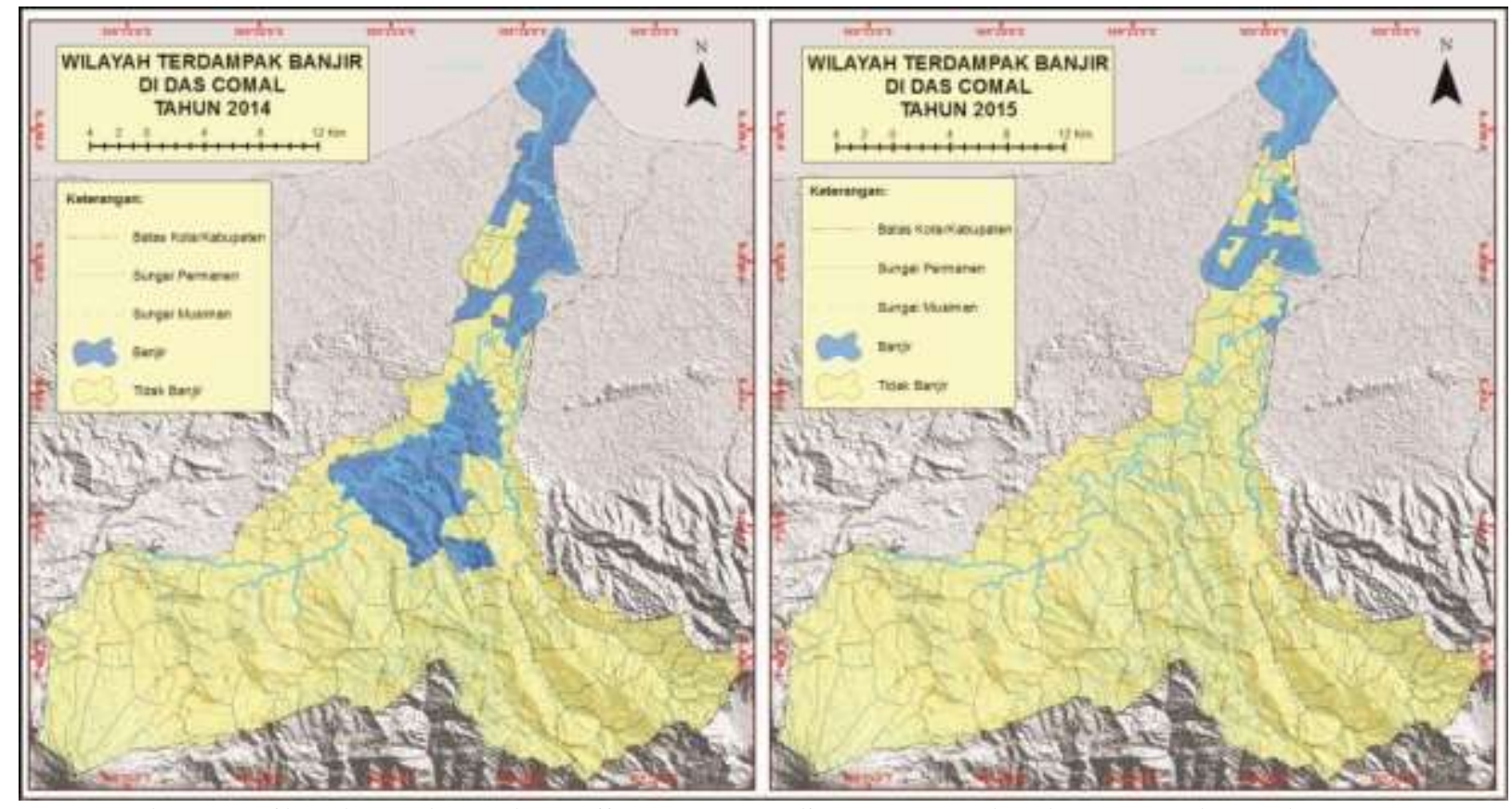

Gambar 2. Wilayah Terdampak Banjir Genangan di DAS Comal Tahun 2014 dan Tahun 2015 (Sumber: diolah dari data kejadian bencana di Kabupaten Pemalang, DINSOSNAKERTRANS dan BPBD Kabupaten Pemalang)

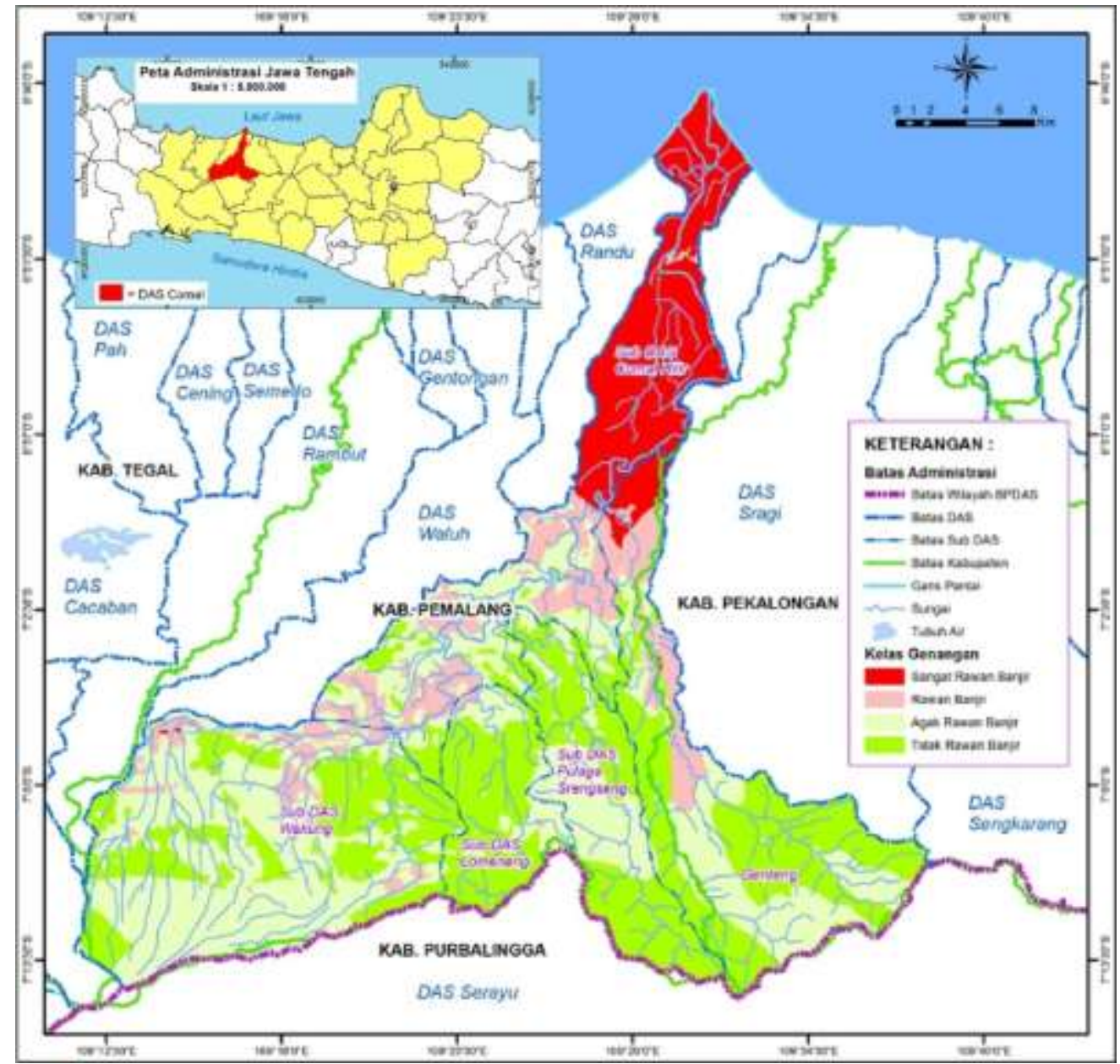

Gambar 3. Peta hasil Pemodelan Banjir Genangan di DAS Comal Tahun 2013

(Balai Pengelolaan Daerah Aliran Sungai (BPDAS), 2013) 


\section{Investigasi komponen risiko terhadap banjir luapan Sungai Comal}

Investigasi komponen risiko dilakukan untuk mengetahui kerentanan wilayah DAS Comal hilir terhadap banjir luapan sungai. Komponen risiko dapat terdiri atas masyarakat, infrastruktur, lahan pertanian, aktivitas-aktivitas sosial, kebudayaan, ekonomi, sarana penghidupan dan sarana prasarana pendidikan (Thieken, Cammerer, Dobler, Lammel, \& Schöberl, 2014). Investigasi terhadap komponen risiko di kawasan rawan bencana banjir sangat penting untuk dilakukan khususnya untuk estimasi kerugian jika bencana banjir melanda dalam rangka untuk mencapai pengelolaan bencana yang tepat. Pengelolaan bencana yang tepat mampu membuat rumusan yang akurat untuk mengurangi potensi kerugian akibat bencana banjir luapan sungai. Analisis komponen risiko akan mendapatkan hasil yang baik dan akurat jika menggunakan data-data dari berbagai sumber, baik data sekunder maupun data primer yang diperoleh langsung di lapangan. Analisis komponen risiko dalam penelitian ini dilakukan dengan mengolah data dari BPS Kabupaten Pemalang untuk data kerentanan sosial, fisik, ekonomi, sedangkan analisis kerentanan lingkungan dilakukan dengan interpretasi CSRT (Tabel 1).

Tabel 1. Komponen risiko dalam analisis kerentanan terhadap banjir luapan sungai di DAS Comal hilir

\begin{tabular}{|c|c|c|c|c|}
\hline No & & Keren & nan & \\
\hline & Sosial & Ekonomi & Fisik & Lingkungan \\
\hline 1. & Kepadatan penduduk & Luas lahan pertanian & Kepadatan bangunan & Luas hutan \\
\hline 2. & Rasio jenis kelamin & $\begin{array}{l}\text { Jumlah industri, pasar dan } \\
\text { pusat kegiatan ekonomi } \\
\text { lainnya }\end{array}$ & Jumlah fasilitas umum & Luas hutan mangrove \\
\hline $\begin{array}{l}3 . \\
4 . \\
5 .\end{array}$ & $\begin{array}{l}\text { Jumlah usia rentan } \\
\text { Penyandang disabilitas } \\
\text { Jumlah penduduk miskin }\end{array}$ & & Jumlah fasilitas kritis & $\begin{array}{l}\text { Luas semak/belukar } \\
\text { Luas rawa }\end{array}$ \\
\hline
\end{tabular}

\section{Kerentanan Sosial}

Kerentanan sosial terhadap banjir luapan sungai di DAS Comal hilir terdiri atas kepadatan penduduk, jumlah penduduk usia rentan, rasio jenis kelamin, jumlah penduduk miskin dan jumlah penyandang disabilitas (Tabel 2). Data-data kependudukan tersebut diperoleh dari BPS Kabupaten Pemalang. Parameter-parameter tersebut merupakan parameter yang relatif paling sering digunakan dalam analisis kerentanan sosial pada berbagai penelitian kenbencanaan karena akan sangat terpengaruh jika bencana banjir melanda. Kepadatan penduduk digunakan sebagai parameter dengan asumsi semakin padat penduduk suatu wilayah maka akan semakin rentan karena potensi jumlah korban terdampak makan semakin besar. Aspek penduduk tidak hanya pada kepadatan saja, tetapi juga jumlah usia rentan, usia rentan adalah penduduk dengan usia di bawah lima tahun dan di atas 65 tahun. Rentang usia tersebut dipilih sesuai dengan estimasi dan beberapa studi kasus bahwa penduduk dengan rentang usia tersebut kurang memiliki kemampuan yang baik untuk menyelamatkan diri ketika bencan melanda. Rasio jenis kelamin merupakan perbandingan antara penduduk laki-laki dan perempuan, asumsi yang digunakan adalah semakin banyak jumlah penduduk perempuan maka wilayah tersebut semakin rentan karena pada umumnya penduduk perempuan lebih rentan berkaitan dengan kemampuan mengatasi bahaya. Jumlah penduduk miskin dan jumlah penyandang disabilitas juga termasuk dalam komponen risiko, dengan asumsi semakin sejahtera penduduk maka memiliki kemampuan dan sarana prasarana untuk menyelamatkan diri dari bencana yang lebih baik, sedangkan penyandang disabilitas cenderung memerlukan bantuan orang lain agar lebih cepat mencapai tempat yang lebih aman. Asumsi-asumsi yang digunakan tersebut berdasarkan beberapa kasus yang telah terjadi dan tidak bermaksud diskriminasi terhadap gender, ras, 
kondisi fisik maupun unsur-unsur negatif lainnya. Hal itu dilakukan dengan tujuan untuk mencapai perencanaan mitigasi bencana yang tepat, sehingga kapasitas masyarakat dapat ditingkatkan untuk menurunkan risiko bencana.

Tabel 2. Kerentanan sosial terhadap banjir luapan sungai di DAS Comal hilir

\begin{tabular}{|c|c|c|c|c|c|c|c|}
\hline \multirow[t]{2}{*}{ Kecamatan } & \multirow{2}{*}{$\begin{array}{l}\text { Luas } \\
\left(\mathbf{k m}^{2}\right)\end{array}$} & \multirow{2}{*}{$\begin{array}{c}\text { Jumlah } \\
\text { Kelurahan/Desa }\end{array}$} & \multicolumn{5}{|c|}{ Populasi Penduduk } \\
\hline & & & $\begin{array}{l}\text { Kepadatan } \\
\text { Penduduk }\end{array}$ & $\begin{array}{c}\text { Jumlah } \\
\text { Penduduk } \\
\text { Usia } \\
\text { Rentan }\end{array}$ & $\begin{array}{c}\text { Rasio } \\
\text { Jenis } \\
\text { Kelamin }\end{array}$ & $\begin{array}{c}\text { Jumlah } \\
\text { penduduk } \\
\text { miskin }\end{array}$ & $\begin{array}{c}\text { Jumlah } \\
\text { Penyandang } \\
\text { Disabilitas }\end{array}$ \\
\hline Ampelgading & 53,30 & 16 & 1239 & 9224 & 97 & 2864 & 410 \\
\hline Bantarbolang & 139,19 & 17 & 512 & 11329 & 93 & 7480 & 497 \\
\hline Bodeh & 85,98 & 19 & 629 & 8673 & 99 & 4618 & 598 \\
\hline Comal & 26,54 & 18 & 3326 & 13119 & 99 & 1427 & 77 \\
\hline Petarukan & 81,29 & 20 & 1793 & 22923 & 98 & 4584 & 333 \\
\hline Ulujami & 60,55 & 18 & 1641 & 15909 & 99 & 3254 & 226 \\
\hline Total & 446,85 & 108 & 9140 & 81177 & 585 & 24227 & 2141 \\
\hline
\end{tabular}

Sumber: Badan Pusat Statistik Kabupaten Pemalang, 2015

\section{Kerentanan Ekonomi}

Kerentanan ekonomi terhadap banjir luapan sungai di DAS Comal hilir terdiri atas parameter luas lahan pertanian dan perikanan (sawah irigasi, tegalan/ladang, tambak ikan, kepiting dan tambak udang), jumlah pasar tradisional dan jumlah industri yang berpotensi terdampak banjir (Tabel 3). Data-data tersebut diperoleh dari interpretasi Citra SPOT 5 yang sudah diuji kebenarannya di lapangan dengan didukung dara dari BPS Kabupaten Pemalang. Parameter-parameter tersebut sangat penting karena berkaitan langsung dengan sarana prasarana penghidupan (livelihood) masyarakat di DAS Comal hilir. Rusak, hilang atau berkurangnya fungsi sarana prasarana penghidupan masyarakat dapat berpengaruh terhadap daya lenting dan kemampuan untuk memulihkan diri pasca bencana. Sarana prasarana penghidupan di DAS Comal hilir terdiri atas lahan pertanian, hal itu karena wilayah hilir DAS Comal merupakan wilayah dataran yang subur. Selain itu, potensi perikanan air payau (tambak) juga sangat berkembang. Lebih lanjut, sebagai wilayah yang mulai berkembang maka jumlah pusat perekonomian seperti pasar, industri maupun pertokoan semakin meningkat. Oleh karena itu, dalam analisis kerentanan ekonomi parameter-parameter tersebut dijadikan sebagai komponen utama.

Tabel 3. Kerentanan ekonomi terhadap banjir luapan sungai di DAS Comal hilir

\begin{tabular}{|c|c|c|c|c|c|c|}
\hline \multirow[t]{2}{*}{ Kecamatan } & \multicolumn{4}{|c|}{ Luas lahan pertanian $\left(\mathrm{km}^{2}\right)$} & \multirow{2}{*}{$\begin{array}{c}\text { Jumlah } \\
\text { Pasar }\end{array}$} & \multirow{2}{*}{$\begin{array}{l}\text { Jumlah } \\
\text { Industri }\end{array}$} \\
\hline & $\begin{array}{c}\text { Sawah } \\
\text { irigasi }\end{array}$ & $\begin{array}{c}\text { Tegalan/ } \\
\text { ladang }\end{array}$ & Hutan & $\begin{array}{c}\text { Kolam/ } \\
\text { Tambak }\end{array}$ & & \\
\hline Ampelgading & 26,07 & 2,50 & 0,00 & 0,000 & 5 & 99 \\
\hline Bantarbolang & 26,96 & 41,45 & 3,65 & 0,000 & 1 & 2 \\
\hline Bodeh & 28,25 & 49,12 & 0,00 & 0,000 & 3 & 72 \\
\hline Comal & 12,30 & 0,76 & 0,37 & 0,000 & 7 & 252 \\
\hline Petarukan & 53,70 & 3,82 & 0,00 & 0,24 & 4 & 122 \\
\hline Ulujami & 22,86 & 12,00 & 2,25 & 13,91 & 0 & 54 \\
\hline Total & 170,14 & 109,65 & 6,27 & 14,14 & 20 & 601 \\
\hline
\end{tabular}

\section{Kerentanan Fisik}

Kerentanan fisik dalam terminologi kebencanaan berkaitan dengan kondisi fisik bangunan yang dimiliki dan yang berada di sekitar masyarakat pada suatu wilayah. Wilayah DAS Comal hilir telah berkembang menjadi pusat pemerintahan, pusat pertumbuhan ekonomi, 
pusat pendidikan, permukiman serta perindustrian sehingga meningkatkan kerentanan wilayah terhadap bencana khususnya banjir. Kerentanan fisik di wilayah tersebut meliputi kepadatan bangunan, jumlah fasilitas umum dan jumlah fasilitas kritis (Tabel 4). Data-data tersebut diperoleh dari BPS Kabupaten Pemalang. Kepadatan bangunan merupakan jumlah semua jenis bangunan dalam satuan $\mathrm{km}^{2}$. Jumlah fasilitas umum merupakan bangunan yang digunakan sebagai tempat aktivitas masyarakat seperti masjid dan sekolah, sedangkan fasilitas kritis merupakan bangunan yang memiliki peran vital bagi masyarakat, yaitu pusat kesehatan seperti rumah sakit, Pusat Kesehatan Masyarakat (PUSKESMAS) dan klinik-klinik kesehatan. Bangunan khususnya permukiman menjadi sangat vital karena merupakan tempat tinggal masyarakat. Fasilitas umum merupakan salah satu tempat yang dapat digunakan sebagai pengungsian sementara maupun untuk koordinasi tanggap darurat bencana, sedangkan fasilitas kritis yang meliputi fasilitas kesehatan menjadi sangat penting dalam manajemen bencana. Oleh karena itu, komponen-komponen tersebut digunakan untuk dasar analisis kerentanan fisik di wilayah DAS Comal hilir.

Tabel 4. Kerentanan fisik terhadap banjir luapan sungai di DAS Comal hilir

\begin{tabular}{|c|c|c|c|}
\hline Kecamatan & $\begin{array}{l}\text { Kepadatan } \\
\text { Bangunan }\end{array}$ & $\begin{array}{c}\text { Jumlah } \\
\text { fasilitas umum }\end{array}$ & $\begin{array}{c}\text { Jumlah } \\
\text { fasilitas kritis }\end{array}$ \\
\hline Ampelgading & 5247 & 244 & 14 \\
\hline Bantarbolang & 752 & 151 & 8 \\
\hline Bodeh & 4135 & 235 & 20 \\
\hline Comal & 4013 & 145 & 9 \\
\hline Petarukan & 4974 & 285 & 0 \\
\hline Ulujami & 574 & 158 & 7 \\
\hline Total & 19695 & 1218 & 58 \\
\hline
\end{tabular}

\section{Kerentanan Lingkungan}

Kerentanan lingkungan merupakan komponen yang terdiri atas layanan lingkungan yang berperan mengurangi dampak dari suatu bahaya. Dalam kasus bencana banjir luapan sungai di DAS Comal hilir, layanan lingkungan berupa hutan budidaya, hutan mangrove, semak dan belukar (Tabel 5). Komponen-komponen tersebut bisa diperttimbangkan sebagai bentuk mitigasi bencana alami. Hal itu menjadi sangat penting karena mampu berperan mengurangi kecepatan aliran banjir dan menahan material yang terbawa oleh aliran banjir sehingga daya rusak banjir dapat dikurangi. Akan tetapi, komponen-komponen tersebut membutuhkan perhatian, perawatan dan pelestarian karena jika mengalami kerusakan maka membutuhkan waktu pemulihan yang relatif lama. Data-data tersebut diperoleh dari interpretasi Citra SPOT 5 yang sudah diuji kebenarannya di lapangan. Komponen lingkungan yang paling dominan di DAS Comal hilir adalah hutan budidaya dan mangrove.

Tabel 5. Kerentanan lingkungan terhadap banjir luapan sungai di DAS Comal hilir

\begin{tabular}{lrrrr}
\multicolumn{1}{c}{ Tabel 5. Kerentanan lingkungan terhadap banjir luapan sungai di DAS Comal hilir } \\
\hline & Luas hutan & Luas rawa & $\begin{array}{c}\text { Luas hutan } \\
\text { mangrove }\end{array}$ & $\begin{array}{c}\text { Luas } \\
\text { semak/belukar }\end{array}$ \\
\hline Ampelgading & 0,000 & 0,000 & 0,000 & 38,796 \\
Bantarbolang & 0,000 & 0,000 & 0,000 & 310,474 \\
Bodeh & 2989,410 & 0,000 & 0,000 & 3,831 \\
Comal & 0,000 & 0,000 & 0,000 & 7,351 \\
Petarukan & 0,000 & 61,166 & 0,000 & 2,882 \\
Ulujami & 0,000 & 180,032 & 34,201 & 1,297 \\
\hline Total & $\mathbf{2 9 8 9 , 4 1 0}$ & $\mathbf{2 4 1 , 1 9 8}$ & $\mathbf{3 4 , 2 0 1}$ & $\mathbf{3 6 4 , 6 3 1}$ \\
\hline
\end{tabular}

Sumber: Badan Pusat Statistik Kabupaten Pemalang, 2015 


\section{Perencanaan Mitigasi Bencana Banjir Non-Struktural}

Wilayah DAS Comal hilir merupakan waterfront city yang cukup berkembang di wilayah kepesisiran Jawa Tengah bagian utara, sehingga wilayah tersebut sangat padat penduduk dan berbagai jenis bangunan. Selain itu, jumlah fasilitas umum, fasilitas kritis, lahan pertanian, jumlah pasar dan industri telah berkembang menjadi faktor vital dalam kehidupan masyarakat. Berdasarkan data-data kerentanan dari berbagai komponen risiko maka dapat disimpulkan bahwa wilayah DAS Comal hilir masuk kategori rentan untuk kerentanan sosial, ekonomi dan fisik. Oleh karena itu, mitigasi non-struktural merupakan salah satu rencana terbaik untuk menanggulangi bencana banjir luapan sungai yang telah menjadi kejadian rutin setiap tahun (Bissett Jr, Huston, \& Navarre, 2018). Mitigasi non-struktural dalam studi ini diperoleh dari hasil studi literatur dan tinjauan antara kejadian bencana banjir luapan sungai di DAS Comal hilir secara temporal maupun spasial, kerentanan terhadap banjir dan beberapa teori berdasarkan kasus yang sama atau hampir sama kejadian bencana di DAS Comal hilir khususnya yang berkaitan dengan peningkatan kapasitas masyarakat dan lingkungan. Hasil analisis dan telaah teori maka bentuk mitigasi non-struktural yang sesuai diterapkan di wilayah DAS Comal hilir adalah perencanaan tata ruang wilayah yang selaras dengan pengelolaan penggunaan lahan di DAS Comal, deteksi dan prediksi kondisi debit Sungai Comal melalui pencatatan serta pengamatan data hidrometeorologi, perencanaan pengelolaan kawasan sempadan sungai, literasi kebencanaan di sekolah dan masyarakat, peningkatan sistem komunikasi dan kearifan lokal dalam masyarakat, pembuatan jalur evakuasi, sistem peringatan dini serta simulasi bencana serta reboisasi dan reforestasi (Allaire, 2018; Kiedrzynska, Kiedrzynski, \& Zalewski, 2014; Singkran, 2017; Ishiwatari, 2019; Ahmed, Haynes, \& Taylor, 2018).

\section{Perencanaan tata ruang wilayah yang selaras dengan pengelolaan penggunaan lahan di DAS Comal}

Perencanaan tata ruang wilayah merupakan wewenang dari pemerintah daerah yang disesuaikan Rencana Tata Ruang Wilayah Nasional. Rencana tata ruang wilayah sebaiknya juga harus disesuaikan dengan pengelolaan DAS, karena batas dan satuan analisis dalam perencanaan tata ruang wilayah dan pengelolaan DAS tidak selaras. Batas dan satuan analisis dalam perencanaan tata ruang wilayah merupakan man-made features yaitu, batas adminitrasi, sedangkan DAS dibatasi oleh natural features yaitu, ppembatas topografi. Oleh karena itu, perencanaan tata ruang wilayah harus dilaksanakan secara holistik karena melibatkan berbagai bidang ilmu dan instansi. Perencanaan tata ruang wilayah dan pengelolaan DAS yang baik dapat mengurangi risiko bencana banjir karena dengan tata ruang yang tepat dan DAS yang sehat maka tata air dalam DAS akan terjaga.

\section{Deteksi dan prediksi kondisi debit Sungai Comal melalui pencatatan serta pengamatan data hidrometeorologi}

Pengamatan data hidrometeorologi dapat digunakan sebagai salah satu dasar analisis untuk mendeteksi dan memprediksi terjadinya banjir. Deteksi dan prediksi banjir sangat membantu untuk proses evakuasi, karena dengan informasi yang lebih dini maka ada waktu yang relatif lebih panjang untuk proses evakuasi. Proses evakuasi menjadi vital karena berkaitan dengan keselamatan masyarakat terdampak, sehingga semakin cepat proses evakuasi maka potensi korban dan kerugian dapat dikurangi. Deteksi dan prediksi kondisi debit dilakukan oleh instansi-instansi yang berwenang dan menyimpan data-data hidrometeorologi. 


\section{Perencanaan pengelolaan kawasan sempadan sungai}

Kawasan sempadan sungai menjadi kawasan yang cukup penting untuk diperhatikan dan dikelola di Indonesia, khususnya berkaitan dengan potensi bencana banjir. Hal itu berkaitan dengan pemanfaatan kawasan sempadan sungai yang tidak sesuai dengan peruntukkanya misalnya sebagai permukiman, tempat usaha bahkan industri maupun peternakan. Pemanfaatan tersebut khususnya untuk permukiman tentu akan meningkatkan kerentanan, sehingga ketika terjadi banjir maka potensi kerugian baik jiwa maupun material akan meningkat. Pengelolaan kawasan sempadan sungai yang baik adalah dengan memperhatikan unsur-unsur eko-hidrolik, peraturan perundang-perundangan yang berlaku dan manfaat dari kawasan tersebut. Namun demikian, pengelolaan kawasan sempadan sungai tetap harus memperhatikan kondisi sosiokultural masyarakat lokal agar pengelolaan terhindar dari konflik dan tujuan utama dari pengelolaan dapat tercapai secara optimal.

\section{Literasi kebencanaan di sekolah dan masyarakat}

Literasi kebencanaan di sekolah-sekolah di wilayah DAS Comal hilir sangat penting dilakukan. Literasi kebencanaan di sekolah dapat dilakukan dengan internalisasi materi kebencanaan dalam pembelajaran seperti pada konsep sekolah-sekolah tangguh bencana, seperti Sekolah Aman Bencana dan sekolah berwawasan lingkungan dan kebencanaan. Tujuan literasi kebencanaan di sekolah adalah memberikan pengetahuan kebencanaan sejak dini pada siswa-siswi agar memiliki pemahaman dan kapasitas yang baik dalam menghadapi bencana khususnya banjir luapan sungai. Siswa-siswi dijadikan sebagai objek dengan tujuan agar informasi tentang kebencanaan yang diperoleh di sekolah dapat ditularkan minimal kepada keluarga inti maupun orang-orang di sekitarnya, sehingga dengan asumsi tersebut maka informasi kebencanaan dapat terdistribusi dengan baik.

Edukasi kebencanaan di masyarakat memiliki konsep yang hampir serupa dengan literasi kebencanaan di sekolah-sekolah, tetapi dengan objek yang berbeda. Edukasi tersebut fokus kepada masyarakat yang artinya edukasi tidak dilakukan secara formal melainkan secara langsung di masyarakat dapat berupa diskusi kelompok terfokus (focused-group discussion) maupun bentuk-bentuk pelatihan lainnya. Edukasi tersebut diharapkan dapat meningkatkan coping capacity melalui peningkatan pengetahuan dan pemahaman masyarakat terhadap bahaya yang berpotensi mengganggu aktivitasnya. Dengan edukasi kebencanaan yang efektif, maka pengetahuan dan pemahaman masyarakat menjadi lebih baik, sehingga coping capacity dapat meningkat dan risiko bencana dapat dikurangi.

\section{Peningkatan sistem komunikasi dan kearifan lokal dalam masyarakat}

Komunikasi dalam masyarakat baik antar individu dengan individu dalam satu keluarga maupun dengan individu di luar keluarga dan kelompok dengan kelompok merupakan aspek penting dalam mitigasi bencana karena dalam penanggulangan bencana tidak hanya dibutuhkan kemampuan dan keahlian tetapi juga kerjasama atau gotong royong. Bentuk komunikasi atau interaksi tersebut merupakan modal sosial yang sangat penting dalam masa prabencana, pada saat bencana dan pasca bencana karena masyarakat dengan komunikasi dan gotong royong yang baik cenderung lebih siap menghadapi bencana dan lebih cepat pulih pasca bencana atau bisa disimpulkan memiliki resiliensi yang baik dari pada masyarakat yang relatif individualis. Komunikasi dalam masyarakat sebenarnya sudah menjadi budaya di Indonesia khususnya bagi masyarakat di wilayah DAS Comal hilir. Akan tetapi bentuk komunikasi sebagai bentuk mitigasi bencana perlu ditingkatkan misalnya melalui internalisasi kegiatan rutin masyarakat seperti rapat rutin warga (rukun tetangga), kerja bakti, arisan, pengajian, karang taruna, Pemberdayaan Kesejahteraan Keluarga (PKK) dan Pos Pelayanan Terpadu (POSYANDU). 
Kearifan lokal telah dilakukan oleh sebagian masyarakat di DAS Comal hilir khususnya oleh para petani tambak. Para petani tambak memiliki patokan waktu tanam benih ikan, udang atau kepiting untuk mempertimbangkan waktu panen dengan potensi terjadinya banjir dengan baik. Hal itu sangat berperan untuk mengurangi kerugian yang diakibatkan banjir luapan sungai. Kearifan lokal dalam bentuk lain yang terus dilakukan adalah gotong royong dalam membuat sarana prasarana untuk mitigasi bencana banjir. Bentuk-bentuk kearifan lokal tersebut harus terus dilestarikan dan perlu diberikan tambahan pengetahuan tentang bencana agar tidak terjadi kesalahan persepsi yang akan menyebabkan masyarakat dan properti yang dimiliki semakin rentan.

\section{Pembuatan jalur evakuasi, sistem peringatan dini serta simulasi bencana}

Penentuan jalur evakuasi harus beriringan dengan penentuan titik kumpul sementara maupun titik pengungsian, dengan tujuan agar alur proses evakuasi dapat berlangsung dengan efektif sehingga potensi jatuhnya korban dapat diminimalisasi. Penentuan jalur evakuasi, titik kumpul dan titik pengungsian harus melalui kajian agar mendapatkan jalur dengan jarak tempuh terdekat dan waktu tempuh tersingkat untuk mencapai titik kumpul yang aman. Selain itu, sosialisasi tentang jalur evakuasi juga harus dilakukan kepada masyarakat sehingga masyarakat mengetahui dan memahami fungsi dari jalur evakuasi tersebut. Jalur evakuasi dapat ditandai petunjuk arah untuk mempermudah proses evakuasi. Penentuan jalur evakuasi dan titik kumpul dapat dilakukan oleh pemerintah dengan melibatkan masyarakat.

Sistem peringatan dini cenderung identik dengan peringatan yang dikirimkan oleh alatalat yang canggih yang dimiliki oleh badan yang berwenang terkait bencana. Namun, sistem tersebut akan lebih efektif dengan penyediaan peralatan yang dapat dipahami oleh masyarakat luas maupun diintegrasikan dengan kearifan lokal masyarakat. Kearifan lokal yang dimaksud adalah bentuk-bentuk komunikasi untuk saling memperingatkan sebelum bencana melanda. Jika kombinasi antara sistem peringatan dini yang didukung teknologi dan kearifan lokal masyarakat dapat terintegrasi dengan naik maka coping capacity dan kesiapsiagaan masyarakat akan meningkat.

Simulasi bencana di DAS Comal hilir masih jarang dilakukan, meskipun upaya tanggap darurat bencana banjir terus dilakukan oleh pemerintah Kabupaten Pemalang, tetapi edukasi dan simulasi belum secara intensif dilakukan. Oleh karena, pelaksanaan Simulasi menjadi penting dilakukan untuk membangun masyarakat tangguh bencana. Pelaksanaan simulasi berkaitan dengan bentuk mitigasi bencana lainnya seperti edukasi, sistem peringatan dini dan pembuatan jalur evakuasi.

\section{Reboisasi dan reforestasi}

Reboisasi dan reforestasi memiliki bentuk aktivitas yang hampir serupa tetapi dengan makna dan tujuan yang sedikit berbeda. Secara sederhana reboisasi merupakan aktivitas penanaman vegetasi lahan kosong yang secara eksisting bukan hutan atau sebelumnya bukan merupakan hutan. Reboisasi dapat diwujudkan dengan pembuatan ruang terbuka hijau seperti di sempadan sungai, hutan kota, taman maupun di lingkungan permukiman. Reforestasi dilakukan dengan tujuan penanaman vegetasi pada area yang sebelumnya merupakan hutan atau penghutanan kembali. Kedua bentuk penanaman vegetasi tersebut dapat berfungsi jangka pendek, menengah dan jangka panjang. Jangka pendek dan menengah sebagai bentuk mitigasi untuk menghambat laju aliran air ketika banjir melanda, jangka panjang untuk menjaga tata air di DAS Comal karena sistem perakaran tumbuhan dapat menjaga agregat tanah sehingga infiltrasi dikawasan hulu menjadi optimal, limpasan menurun dan berimplikasi terhadap penurunan laju erosi yang dapat menyebabkan pendangkalan sungai yang berdampak langsung terhadap kejadian banjir luapan sungai (Wyżga, Kundzewicz, Konieczny, Piniewski, 
Zawiejska, \& Radecki-Pawlik, 2018). Pelaksanaan reboisasi dan reforestasi harus dilakukan dengan sinergi antara pemerintah dan masyarakat, sehingga kegiatan tersebut tidak hanya berhenti pada tahap penanaman saja tetapi juga perawatan.

\section{Kesimpulan}

Perencanaan mitigasi bencana banjir non-struktural di DAS Comal hilir diharapkan mampu membangun masyarakat tangguh bencana yang memiliki daya lenting (resilience) yang baik. Rekaman kejadian dan hasil pemodelan BPDAS Pemali-Jratun menunjukkan bahwa wilayah DAS Comal hilir sangat rawan banjir luapan Sungai Comal dan mengalami bencana terparah pada Tahun 1980 dan 2014. Data kerentanan terhadap banjir yang terdiri atas kerentanan sosial, ekonomi, fisik dan lingkungan. Wilayah DAS Comal hilir sangat rentan dari sisi sosial, ekonomi dan fisik. Hasil analisis menghasilkan perencanaan mitigasi bencana banjir non-struktural dalam bentuk perencanaan tata ruang wilayah yang selaras dengan pengelolaan penggunaan lahan di DAS Comal, deteksi dan prediksi kondisi debit Sungai Comal melalui pencatatan serta pengamatan data hidrometeorologi, perencanaan pengelolaan kawasan sempadan sungai, literasi kebencanaan di sekolah dan masyarakat, peningkatan sistem komunikasi dan kearifan lokal dalam masyarakat, pembuatan jalur evakuasi, sistem peringatan dini serta simulasi bencana serta reboisasi dan reforestasi. Perencanaan mitigasi tersebut tidak hanya menjadi tanggung jawab pemerintah saja, melainkan membutuhkan kesadaran dan kerjasama dari masyarakat.

\section{Ucapan Terimakasih}

Ucapan terima kasih disampaikan kepada Badan Perencanaan Pembangunan Daerah (BAPPEDA), Dinas Pekerjaan Umum (DPU), Badan Penanggulangan Bencana Daerah (BPBD), Dinas Sosial, Tenaga Kerja dan Transmigrasi (DINSOSNAKERTRANS) Kabupaten Pemalang serta masyarakat di wilayah DAS Comal Kabupaten Pemalang yang telah mendukung dan membantu kelancaran dalam menyelesaikan penulisan artikel ini.

\section{Daftar Rujukan}

Ahmed, M. A., Haynes, K., \& Taylor, M. (2018). Driving into floodwater: A systematic review of risks, behaviour and mitigation. International Journal of Disaster Risk Reduction, 31, 953-963.

Allaire, M. (2018). Socio-economic impacts of flooding: A review of the empirical literature. Water Security, 3, 18-26.

Asian Disaster Preparedness Center (ADPC). (2005). Integrated Flood Risk Management in Asia. Bangkok, Thailand: Asian Disaster Preparedness.

Badan Nasional Penanggulangan Bencana. (2012). Pedoman Umum Pengkajian Risiko Bencana. Jakarta: Badan Nasional Penanggulangan Bencana.

Badan Perencanaan Pembangunan Daerah Provinsi Jawa Tengah. (2005). Buku Pegangan Untuk Penanggulangan Bencana Di Provinsi Jawa Tengah: Banjir, Tanah Longsor, Kekeringan, dan Tsunami (di Indonesia). Semarang, Jawa Tengah: BAPPEDA Provinsi Jawa Tengah.

Balai Pengelolaan Daerah Aliran Sungai (BPDAS). (2013). (B. Pemali-Jratun, Produser) Dipetik Januari 5, 2015, dari www.bpdas-pemalijratun.net: http://www.bpdaspemalijratun.net/index.php?option=com_content\&view $=$

Bissett Jr, W., Huston, C., \& Navarre, C. B. (2018). Preparation and Response for Flooding Events in Beef Cattle. Veterinary Clinics of North America: Food Animal Practice, 34(2), 309-324. 
Ishiwatari, M. (2019). Flood risk governance: Establishing collaborative mechanism forintegrated approach. Progress in Disaster Science, 2.

Itsukushima, R. (2018). Countermeasures against floods that exceed design levels based on topographical and historical analyses of the September 2015 Kinu River flooding. Journal of Hydrology: Regional Studies, 19, 211-223.

Jamrussri, S., \& Toda, Y. (2017). Simulating past severe flood events to evaluate the effectiveness of nonstructural flood countermeasures in the upper Chao Phraya River Basin, Thailand. Journal of Hydrology: Regional Studies, 10, 82-94.

Kai, W., Deyi, C., \& Zhaohui, Y. (2016 ). Flood control and management for the transitional Huaihe River in China. Dalam P. Engineering (Penyunt.), 12th International Conference on Hydroinformatics, HIC 2016. 154, hal. 703 - 709. Elsevier Ltd. .

Keputusan Menteri Kehutanan dan Perkebunan. (2009). Tentang penetapan urutan prioritas Daerah Aliran Sungai (Vol. 328/Kpts-II/). Kementerian Kehutanan dan Perkebunan Republik Indonesia.

Kiedrzynska, E., Kiedrzynski, M., \& Zalewski, M. (2014). Sustainable floodplain management for flood prevention and water quality improvement. Journal of Natural Hazards, 76, 955-977.

Kumpulainen, S. (2006). Vulnerability Concepts in Hazard and Risk Assessment. Special Paper.

Marfai, M. A., King, L., Singh, L. P., Mardiatno, D., Sartohadi, J., Hadmoko, D. S., et al. (2008). Natural Hazards In Central Java Province, Indonesia: An Overview. Journal of Enviroment Geoscience, 56(2), 335-351.

Reisenbüchler, M., Bui, M. D., Skublics, D., \& Rutschmann, P. (2019). An integrated approach for investigating the correlation between floods and river morphology: A case study of the Saalach River, Germany. Science of the Total Environment, 647, 814-826.

Rezende, O. M., de Franco, A. B., de Oliveira, A. K., Jacob, A. C., \& Miguez, M. G. (2019). A framework to introduce urban flood resilience into the design of flood control alternatives. Journal of Hydrology, 576, 478-493.

Singkran, N. (2017). Flood risk management in Thailand: Shifting from a passive to a progressive paradigm. International Journal of Disaster Risk Reduction, 25, 92-100.

Thieken, A. H., Cammerer, H., Dobler, C., Lammel, J., \& Schöberl, F. (2014). Estimating changes in flood risks and benefits of non-structural adaptation strategies - a case study from Tyrol, Austria. Mitigation Adaptation Strategy Global Change, 10, 1007-1027.

United Nations International Strategy for Disaster Reduction (UNISDR). (2009). UNISDR Terminology on Disaster Risk Reduction. Geneva: United Nations International Strategy for Disaster Reduction.

Westen, C. v., Kingma, N., \& Montoya, A. M. (2009). Elements at risk. In:Multi-hazard Risk Assessment. United Nations University - ITC School on Disaster Geoinformation.

Wyżga, B., Kundzewicz, Z. W., Konieczny, R., Piniewski, M., Zawiejska, J., \& RadeckiPawlik, A. (2018). Comprehensive approach to the reduction of river flood risk: Case study of the Upper Vistula Basin. Science of the Total Environment, 631-632, 12511267. 